\title{
Frequency of abdominal aortic aneurysm in persons who have been examined with ultrasound at Kasr Al-Ainy Hospitals: a single center pilot study
}

\author{
Ahmed A. Shaker, Hussein Mahmoud Khairy, Khaled H. Elkaffas, Ahmad Abdelhafez Ghanem \\ Kasr Al-Ainy Medical School, Cairo University, Cairo, Egypt
}

\begin{abstract}
Introduction: To know frequency of abdominal aortic aneurysm (AAA) using ultrasound and clarify associated risk factors in 1000 Egyptians.

Material and methods: Prospective study. 1000 patients aged 50 years or more (mean: $57.97 \pm[7.68]$ ) were examined by $B$-mode ultrasound at our radiology department to measure suprarenal maximum diameter of the abdominal aorta (wall to wall measurement) and to identify the occurrence of AAA (aneurysms were defined as 1.5 times the mean diameter). Demographic data and risk factors were also noted.

Results: Mean aortic diameter in study population was $18.9 \pm$ (3.2) mm. AAA diameter was $28.3 \mathrm{~mm}$. Frequency of AAA was $1.5 \%$. AAA prevalence: $2.35 \%$ in males versus $0.75 \%$ in females. Prevalence of AAA in different age groups: $<60$ years $(n=653), 60-70(n=282),>70$ years $(n=65)$ was $6(0.9 \%), 6(2.1 \%), 3(4.6 \%)$ respectively. Patients with AAA were older $(P<0.001)$, more often male $(P<0.00$ I), smokers $(P<0.00$ I). Conclusion: Study showed that mean aortic diameter was $18.9 \mathrm{~mm}$ and AAA is present in $1.5 \%$ of the study population which was less than that seen in previously conducted studies in other countries.
\end{abstract}

Key words: abdominal aortic aneurysm, ultrasound, prevalence, hypertension

Acta Angiol 2019; 25, 3: 133-139

\section{Introduction}

Abdominal aortic normal diameter is about $2 \mathrm{~cm}$. If any part of the aorta has a diameter of $>3 \mathrm{~cm}$ is called abdominal aortic aneurysm [ $\mathrm{I}]$.

The incidence of abdominal aortic aneurysms (AAAs) increases tremendously in the presence of any factors like age more than 60 years, smoking, hypertension and Caucasians. The incidence of an aneurysm to rupture is influenced by the aneurysm size, expansion rate, continued smoking and persistent elevated blood pressure [2].

Most of AAAs are asymptomatic and are detected as an accidental finding on abdominal ultrasonography, computed tomography on the abdomen or magnetic resonance imaging done for other purposes. It can present with pain in the abdomen or complications as thrombosis, embolization and rupture. $30 \%$ of asymptomatic AAAs is discovered as a pulsatile mass in the abdomen on routine physical examination [3].

The main screening modality for abdominal aortic aneurysm screening is the abdominal ultrasound (the gold standard for screening). It is sensitive and specific with low cost as well as high safety [4].

In men from 65-75 years with a positive smoking history, the recommendation: grade $B$ for one-time screening for AAA with abdominal ultrasound (The United States Preventive Task Force Service) [4].

Management for patients with an asymptomatic AAA includes: decreasing risk factors such as smoking, elevated blood pressure and hyperlipidemia, medical therapy with beta-blockers, conservative, endovascular aortic stenting, and open repair depending on the size and expansion rate of the aneurysm and comorbidities [3]. 


\section{Material and methods}

\section{Study design}

This is a prospective study which started on the $I^{\text {st }}$ of September 2017 to March 2018. It was conducted at Radiology Department, Kasr Al Ainy hospitals. I,000 patients undergoing elective abdominal ultrasonography for diverse indications had measurement of the diameter of the suprarenal aorta. An aneurysm is usually defined as an outer aortic diameter more than $50 \%$ of normal diameter or more than $30 \mathrm{~mm}$ in diameter [5]. In this study aneurysm was defined as those with a maximum diameter 1.5 times the mean diameter of the suprarenal aorta (the cut off value was $28.3 \mathrm{~mm}$ ). All subjects provided oral informed consent to enter in this study.

\section{Study population}

The inclusion criteria were: I) the age at or above 50 years old and 2) individuals having Ultrasound at radiology department (elective). The exclusion criteria were: I) the age less than 50 years old; 2 ) a history AAA.

\section{Ultrasound examinations}

With the patient in the supine position, the examination was performed using the B-mode of ultrasound. The curvilinear transducer 3.5 MHZ giving its lower frequency and deeper penetration was used $[6,7]$. The suprarenal abdominal aorta was visualized in the transverse and longitudinal planes and maximum diameter from either anteroposterior or transverse diameter was taken. Indications of ultrasound examination were classified into those for non-vascular symptoms and those with vascular symptoms. Data collected included indication of ultrasound examination, age, gender; medical history (smoking, diabetes mellitus [DM], hypertension [HTN], ischemic heart disease [IHD], peripheral vascular disease [PVD]), surgical history and the diameter of the suprarenal aorta were obtained.

\section{Statistical analysis}

The quantitative data were described as a mean \pm standard deviation (SD) or median with interquartile range (IQR) according to the normality of sample distribution; while qualitative data were described as frequency or percentage.

Tests of associations for quantitative data were either independent $t$-test, or non-parametric Mann-Whitney $U$ test according to the normality of sample distribution. Chi-square was used to compare the difference in quantitative data. SPSS version 22 for windows was used for statistical analysis. P-value less than 0.05 was considered statistically significant.

\section{Results}

Only $21 \%(210)$ of the individuals enrolled in this study had vascular symptoms while the other $79(790) \%$ had no vascular symptoms (Table I). The mean suprarenal aortic diameter was found to be $18.9 \mathrm{~mm}$ (3.2). In this study, aneurysms were defined as 1.5 times the mean that i.e. more than $28.3 \mathrm{~mm}$ _rather than the standard $30 \mathrm{~mm}$. Considering this definition, fifteen individuals were found to have AAA that i.e. a prevalence of $1.5 \%$ in the studied population

\section{Abdominal aortic diameter in relation to different risk factors}

Increasing of the diameter of abdominal aorta and also People with AAA had an increased prevalence of smoking habit $(P<0.00 \mathrm{I})$ and hypertension $(\mathrm{P}>0.00 \mathrm{I})$, but not of DM ( $P=0.208)$ (Table 2).

Also, the increasing of diameter of abdominal aorta and the occurrence of AAA in the study population was associated with less incidence of PVD $(P<0.00 I)$ and CAD $(P<0.00 I)$ (Table 2).

\section{Correlation between aortic diameter and age}

There is a direct relationship between age and aortic diameter with correlation coefficient is $0.196(P>0.001)$.

Table I. Indication for US of individuals enrolled in the study

\begin{tabular}{|l|c|c|}
\hline Indication for US & Total $(\mathrm{n}=1000)$ & - \\
\hline Upper GIT symptoms (\%) & $114(11.4 \%)$ & $6(40 \%)$ \\
\hline Upper and Lower GIT symptoms (\%) & $212(21.2 \%)$ & - \\
\hline Lower GIT symptoms (\%) & $37(3.7 \%)$ & $3(20 \%)$ \\
\hline Lower GIT and Urinary symptoms (\%) & $12(1.2 \%)$ & $4(26.6 \%)$ \\
\hline Urinary symptoms (\%) & $169(16.9 \%)$ & $1(6.7 \%)$ \\
\hline Vascular symptoms (\%) & $210(21 \%)$ & $1(6.7 \%)$ \\
\hline Follow up for malignancy (\%) & $68(6.8 \%)$ & $177(17.7 \%)$ \\
\hline Other symptoms (\%) & & AAA \\
\hline
\end{tabular}


Table 2. Demographic and clinical characteristics of patients enrolled in the study

\begin{tabular}{|c|c|c|c|}
\hline Characteristic/population & Total $(n=1000)$ & AAA $(n=15)$ & $\begin{array}{l}\text { P-value of the characteristic (total) in relation to } \\
\text { abdominal aortic diameter and AAA prevalence }\end{array}$ \\
\hline $\begin{array}{l}\text { Aortic diameter } \\
\qquad \begin{array}{l}\text { I. Mean (SD) } \\
\text { 2. Median (IQR) }\end{array}\end{array}$ & $\begin{array}{c}18.92(3.205) \\
18.2(17.3-19.3)\end{array}$ & $\begin{array}{l}34.42(7.97) \\
31.4(29-39)\end{array}$ & - \\
\hline $\begin{array}{l}\text { Age in years } \\
\text { I. Mean (SD) } \\
\text { 2. Median (IQR) }\end{array}$ & $\begin{array}{c}57.97(7.68) \\
56(52-6 I)\end{array}$ & $\begin{array}{l}61.6(11.86) \\
60(50-70)\end{array}$ & $>0.001$ \\
\hline $\begin{array}{l}\text { Age category } \\
\qquad \begin{array}{l}\text { I. }>60 \text { years }(\%) \\
\text { 2. } 60-70 \text { years }(\%) \\
\text { 3. }<70 \text { years }(\%)\end{array}\end{array}$ & $\begin{array}{c}653(65.3 \%) \\
282(28.2 \%) \\
65(6.5 \%)\end{array}$ & $\begin{array}{l}6(40 \%) \\
6(40 \%) \\
3(20 \%)\end{array}$ & $>0.001$ \\
\hline $\begin{array}{l}\text { Gender } \\
\text { I. Male (\%) } \\
\text { 2. Female (\%) }\end{array}$ & $\begin{array}{l}468(46.8) \\
532(53.2)\end{array}$ & $\begin{array}{l}\text { II (73.3\%) } \\
4(26.7 \%)\end{array}$ & $>0.001$ \\
\hline $\begin{array}{l}\text { Hypertension } \\
\text { I. No (\%) } \\
\text { 2. Yes (\%) }\end{array}$ & $\begin{array}{l}611(61.1 \%) \\
389(38.9 \%)\end{array}$ & $\begin{array}{l}6(40 \%) \\
9(60 \%)\end{array}$ & $>0.001$ \\
\hline $\begin{array}{l}\text { DM } \\
\text { I. No (\%) } \\
\text { 2. Yes (\%) }\end{array}$ & $\begin{array}{l}511(51.1 \%) \\
489(48.9 \%)\end{array}$ & $\begin{array}{l}8(53.3 \%) \\
7(46.7 \%)\end{array}$ & 0.208 \\
\hline $\begin{array}{l}\text { Smokers } \\
\qquad \begin{array}{l}\text { I. No (\%) } \\
\text { 2. Yes (\%) }\end{array}\end{array}$ & $\begin{array}{l}661(66.1 \%) \\
339(33.9 \%)\end{array}$ & $\begin{array}{c}5(33.3 \%) \\
10(66.7 \%)\end{array}$ & $>0.001$ \\
\hline $\begin{array}{l}\text { IHD } \\
\qquad \begin{array}{l}\text { I. No (\%) } \\
\text { 2. Yes (\%) }\end{array}\end{array}$ & $\begin{array}{l}776(77.6 \%) \\
224(22.4 \%)\end{array}$ & $\begin{array}{l}9(60 \%) \\
6(40 \%)\end{array}$ & $>0.001$ \\
\hline $\begin{array}{l}\text { PVD } \\
\qquad \begin{array}{l}\text { I. No (\%) } \\
\text { 2. Yes (\%) }\end{array}\end{array}$ & $\begin{array}{l}875(87.5 \%) \\
125(12.5 \%)\end{array}$ & $\begin{array}{l}10(66.7 \%) \\
5(33.3 \%)\end{array}$ & $>0.001$ \\
\hline
\end{tabular}

People with AAA were older than the total population of the study (mean age was 61.6 and 57.6 for both groups respectively).

\section{Difference in aortic diameter across different age categories}

Total population $(\mathrm{n}=1,000)$ was divided into three subgroups according to age as follow: $<60$ Years $(n=653), 60-70(n=282),>70$ years $(n=65)($ Table 2$)$ and the mean aortic diameter for each age subgroup was (18.59, 19.16, 21.25) mm respectively (Fig. I) and the number \& prevalence of AAA in each subgroup was $6(0.9 \%), 6(2.1 \%), 3(4.6 \%)$ respectively. So, the more the age, the more the mean aortic diameter and prevalence of AAA.
Mean aortic diameter and AAA prevalence across gender

Mean aortic diameter for males $(19.27 \mathrm{~mm})$ was higher than females (I8.6I mm) with (P>0.00I) (Fig. 2) and AAA was found to be more in males $(73.3 \%)$. AAAs prevalence in males vs. females was $2.35 \%$ vs. $0.75 \%$ respectively (Fig. 2 ).

\section{Classification of patients with AAA in relation to the aneurysmal size}

People with AAA classified according to aortic diameter in mm into three subgroups; 28.3: 39.99, 40:50, > $50 \mathrm{~mm}$. The number and\% in each subgroup were 12 (80\%), 2 (I3.3\%), I (6.7\%) respectively.

Smallest and Largest obtained aneurysmal diameters were 28.8 and $59 \mathrm{~mm}$ respectively. 


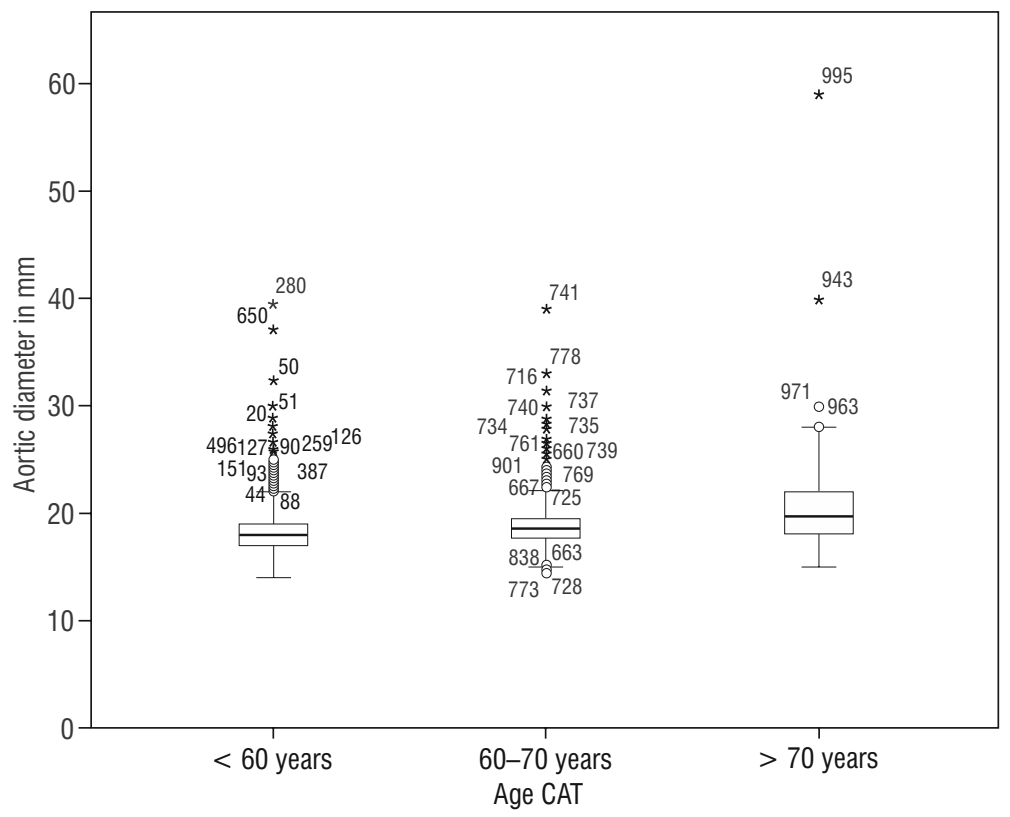

Figure I. The difference in aortic diameter across different age categories

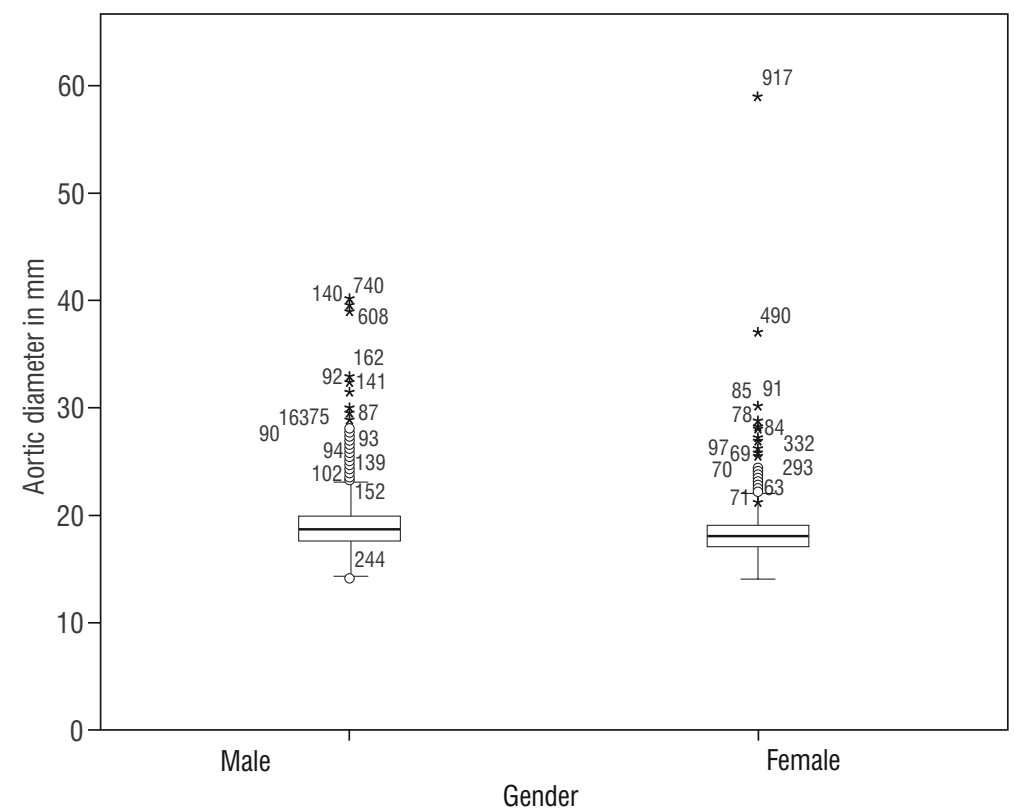

Figure 2. Difference in aortic diameter in relation to genders

The size distribution of AAA

in different age groups

Classification of aneurysmal diameter in different age categories was:

I. <60 years $(n=6)$, all diameters from 28.3:39.99 mm

2. 60-70 $(n=6)$, apart from one person $<50 \mathrm{~mm}$ $(59 \mathrm{~mm})$, the other five persons have diameters from 28.3:39.99 mm.

3. $>70$ years $(n=3)$, apart from one person with diameters from 28.3:39.99 $\mathrm{mm}$. the other two persons have diameters from $40: 50 \mathrm{~mm}$.
Frequency of AAA among western counties as shown in Table 3.

\section{Discussion}

As to the best of our knowledge, there is no data regarding the prevalence of AAA in the Egyptian population and even the mean aortic diameter has not been studied. We set to study these two parameters starting as a study of 1000 individuals presenting to have abdominal ultrasonography at radiology department (elective). 
Table 3. Frequency of AAA among western countries

\begin{tabular}{|c|c|c|c|c|}
\hline Age-Gender prevalence & Australia & Norway & Japan & Sweden \\
\hline \multicolumn{5}{|l|}{ Men } \\
\hline $60-69$ years & \multirow{3}{*}{$7.2 \%$} & - & $1.6 \%$ & - \\
\hline 70-79 years & & \multirow{2}{*}{$19.8 \%$} & $5.7 \%$ & $2.3 \%$ \\
\hline$>80$ years & & & $9.2 \%$ & - \\
\hline \multicolumn{5}{|l|}{ Women } \\
\hline $60-69$ years & - & - & $0.6 \%$ & - \\
\hline 70-79 years & - & \multirow{2}{*}{$5-2 \%$} & $1.3 \%$ & $0.4 \%$ \\
\hline$>80$ years & - & & $5.7 \%$ & - \\
\hline
\end{tabular}

The introduction of population-based screening reduced mortality associated with AAA by $45 \%$ [8].

In this study, mean aortic diameter was $(18.9 \mathrm{~mm})$, total population $(\mathrm{n}=1,000)$ was divided into three subgroups according to age as follow: $<60$ years $(n=653), 60-70(n=282),>70$ years $(n=65)$ (Table 3$)$ with mean aortic diameter for each age subgroup is (18.59, 19.16, 21.25) respectively.

The Gloucestershire Aneurysm Screening Programme (GASP) started in 1990. During the 25 years of the study, mean aortic diameter in 65-year-old men fell from around $2.0 \mathrm{~cm}$ in the early $1990 \mathrm{~s}$, to about $1.7 \mathrm{~cm}$ in 2010-20I5 (estimated reduction of 12 per cent over 25 years; $\mathrm{P}<0.00 \mathrm{I}$ ) [9]. Most of the available data regarding the prevalence of AAA has been derived from studies in Western countries [10-12]. In our study aneurysm was defined as those with a maximum diameter one and half times the mean suprarenal aorta diameter (the cut off value was $28.3 \mathrm{~mm}$ ). Considering the mean diameter, the prevalence of AAA in our study was $1.5 \%(15 / 1,000)$. This prevalence may be less if we considered mean abdominal aortic diameter was $20 \mathrm{~mm}$ and consequentially AAA diameter was $30 \mathrm{~mm}$. Four large randomized controlled trials between 1988 and 1999 reported AAA prevalence rates from $4-7.2 \%$ on US screening [13-16]. However, more recent studies seem to indicate a decreasing prevalence to $\mathrm{I} . \mathrm{I}-2.6 \%$ $[17,18]$. It therefore appears that the epidemiology has changed over the years with a progressive decline of disease prevalence. This could be due to an improved risk factor management (especially of smoking which is the most modifiable risk factor) [19]. In our study, age-specific prevalence of AAA in each subgroup is (0.9\%), (2.1\%), (4.6\%) respectively, similarly when screening 70-year-old men in Sweden (2.3\%) [20]. While in Australia, prevalence of AAA was (7.2\%) in population aged between 65 and 83 years [16]. Like Norway, AAA was found in $19.8 \%$ and $5.2 \%$ of men and women aged $75-84$ years, respectively [12]. Taken together, the previous results suggest that our findings ( $2.35 \%$ and $0.75 \%$ prevalence, respectively in men and women) were too low and that the prevalence of AAA in our study population seems to be less than that in Western populations as shown in table 3.

Moreover, in this study, the prevalence of AAA was found to increase according to age, regardless of gender which was the same in accordance to a population-based study from Japan [2I]. Overall, the prevalence of AAA in our population was statistically higher in males vs. females $(2.35 \%$ vs. $0.75 \%, P>0.00 I)$. In published studies female consistently display lower prevalence rates for AAAs than men of the same age, with roughly $\mathrm{I} / 4$ to $\mathrm{I} / 6$ of that of men. [2I, 22]. A new screening study in Sweden of 5140 women showed an AAA prevalence of $0.4 \%$ only among 70-year-old women [23]. Although the prevalence of AAA appears to be lower in women, but they seem at higher risk for complications. In the UK Small Aneurysm Trial: AAA between 4.0 and $5.4 \mathrm{~cm}$, women had three times more rupture rate compared with men with equal diameter [22]. As regarding risk factors, patients with AAA were often males $(P<0.00 \mathrm{I})$, old age $(P<0.00 I)$, smokers [current]. $(P<0.00 I)$ and hypertensive $(P<0.001)$. In a prospective study of 18782 individuals aged above 65 years, smoking was found to be a major and the strongest risk factor for incident $\mathrm{AAA}$, with a strong and similar association between men and women [24].

Another study also reports an increasing prevalence of AAA with age and smoking, particularly for current smokers where the prevalence appears to be over $2 \%$. Of all the cardiovascular disorders, smoking was found to be a major and the strongest associated risk factor with AAA [25].

On contrary to smoking, which was a powerful risk factor for AAA in both men and women, hypertension was the prevalant risk factor in women of all ages. Only two $(7 \%)$ of 28 women with an acute AAA were 
normotensive, compared with 31 (4I\%) of 75 men $(\mathrm{P}<0.00 \mathrm{I})[26]$.

In study by Chun et al., 2014 [27]. that had 6,142 patients (age: $72.7 \pm 5.3$ years) were screened for AAA from early 2007 and late 2009. (7.6\%) 469 patients with AAA prevalence of CAD with AAA (male $43.1 \%$ vs. female $28.5 \% ; P<0.00 I$ ) and PVD with AAA (male $37.3 \%$ vs. female $7.7 \%$; $P<0.00 \mathrm{I}$ ). It was not similar to our study in which there was low incidence of $C A D$ $(P<0.00 I)$ and PVD $(P<0.00 I)$ in individuals with AAA. Risk factors closely linked with normal aortic size were the association with diabetes (I8.6\% vs. $27.4 \%$; $P<0.00 I$ ) [27]. We found association of $D M$ in relation to aortic diameter had insignificant $P$-value $(p=0.208)$. Also number of people with AAA who are DM vs. non DM is $8 / 15$ (53.3\%) vs. $7 / 15$ (46.6\%) which suggests that DM not associated with AAA as risk factor.

\section{Conclusions}

It was concluded that the mean diameter of the suprarenal aorta was $18.92 \mathrm{~mm}$. Considering this mean, the prevalence of AAA in this study population was $1.5 \%$ (lesser than in other studies) with a prevalence of $2.35 \%$ in males vs. $0.75 \%$ in females. The prevalence increases with age. Patients with AAA were older $(\mathrm{P}<0.00 \mathrm{I})$, more often male $(\mathrm{P}<0.00 \mathrm{I})$, smokers $(P<0.00 \mathrm{I})$, hypertensive $(P<0.00 \mathrm{I})$. The incidence of $D M$ in individuals with $A A A$ is less than those without $(P=0.208)$. The incidence of CAD and PVD in people with $A A A$ is less than those without $(P<0.001)$. Patients with AAA are older, more often male, smoker and hypertensive.

\section{Conflict of interest}

None.

\section{References:}

I. McPhee JT, Hill JS, Eslami MH. The impact of gender on presentation, therapy, and mortality of abdominal aortic aneurysm in the United States, 200I-2004. J Vasc Surg. 2007; 45(5): 89I-899, doi: 10.1016/j.jvs.2007.01.043, indexed in Pubmed: 17391899.

2. Parkinson F, Ferguson S, Lewis P, et al. South East Wales Vascular Network. Rupture rates of untreated large abdominal aortic aneurysms in patients unfit for elective repair. J Vasc Surg. 2015; 6I(6): 1606-1612, doi: 10.1016/j.jvs.2014.10.023, indexed in Pubmed: 2566I72I.

3. Robertson L, Atallah E, Stansby G. Pharmacological treatment of vascular risk factors for reducing mortality and cardiovascular events in patients with abdominal aortic aneurysm. Cochrane Database Syst Rev. 2014(I): CD0 10447, doi: 10.1002//465 I858. CD010447.pub2, indexed in Pubmed: 24449038.

4. Chung, J. Epidemiology, risk factors, pathogenesis, and natural history of abdominal aortic aneurysm. https://www.uptodate. com/contents/epidemiology-risk-factors-pathogenesis-and-natural-history-of-abdominal-aortic-aneurysm.

5. Kent KC. Clinical practice. Abdominal aortic aneurysms. N Engl J Med. 2014; 37I (22): 210I-2108, doi: 10.1056/NEJMcp I 40I430, indexed in Pubmed: 25427II 2.

6. Ali MU, Fitzpatrick-Lewis D, Miller J, et al. Screening for abdominal aortic aneurysm in asymptomatic adults. J Vasc Surg. 2016; 64(6): 1855-1868, doi: 10.1016/j.jvs.2016.05.101, indexed in Pubmed: 2787/502.

7. Zaidman CM, van Alfen N. Ultrasound in the Assessment of Myopathic Disorders. J Clin Neurophysiol. 2016; 33(2): 103-III, doi: 10.1097/WNP.0000000000000245, indexed in Pubmed: 27035250

8. Dereziński TL, Fórmankiewicz B, Migdalski A, et al. The prevalence of abdominal aortic aneurysms in the rural/urban population in central Poland - Gniewkowo Aortic Study. Kardiol Pol. 2017; 75(7): 705-710, doi: 10.5603/KP.a2017.007I, indexed in Pubmed: 28394003.

9. Oliver-Williams C, Sweeting MJ, Turton G, et al. Gloucestershire and Swindon Abdominal Aortic Aneurysm Screening Programme. Lessons learned about prevalence and growth rates of abdominal aortic aneurysms from a 25-year ultrasound population screening programme. Br J Surg. 2018; 105(I): 68-74, doi: 10.1002/bjs. 107/5, indexed in Pubmed: 29265406.

10. Argyriou C, Georgiadis GS, Kontopodis N, et al. Screening for Abdominal Aortic Aneurysm During Transthoracic Echocardiography: A Systematic Review and Meta-analysis. Eur J Vasc Endovasc Surg. 2018; 55(4): 475-49।, doi: 10.1016/j. ejvs.2018.01.003, indexed in Pubmed: 29433798.

I I. Aboyans V, Bataille V, Bliscaux P, et al. investigators of the E2T3A study. Effectiveness of screening for abdominal aortic aneurysm during echocardiography. Am J Cardiol. 2014; II4(7): I 100 - I 104, doi: 10. 1016/j.amjcard.2014.07.024, indexed in Pubmed: 25127549.

12. Singh K, Bønaa KH, Jacobsen BK, et al. Prevalence of and risk factors for abdominal aortic aneurysms in a population-based study : The Tromsø Study. Am J Epidemiol. 200 I; 154(3): 236-244, doi: 10.1093/aje/I54.3.236, indexed in Pubmed: I 1479|88.

13. Scott RA, Wilson NM, Ashton HA, et al. Influence of screening on the incidence of ruptured abdominal aortic aneurysm: 5-year results of a randomized controlled study. $\mathrm{Br}$ J Surg. 1995; 82(8): 1066-1070, doi: 10.1002/bjs. 1800820821 , indexed in Pubmed: 7648155.

14. Scott R. The Multicentre Aneurysm Screening Study (MASS) into the effect of abdominal aortic aneurysm screening on mortality in men: a randomised controlled trial. The Lancet. 2002; 360(9345): |53|-1539, doi: 10.1016/50|40-6736(02)। | 522-4.

15. Lindholt JS, Juul S, Fasting $\mathrm{H}$, et al. Hospital costs and benefits of screening for abdominal aortic aneurysms. Results from a randomised population screening trial. Eur J Vasc Endovasc Surg. 2002; 23(I): 55-60, doi: 10.1053/ejvs.2001.1534, indexed in Pubmed: I 1748949.

16. Norman PE, Jamrozik K, Lawrence-Brown MM, et al. Population based randomised controlled trial on impact of screening on mortality from abdominal aortic aneurysm. BMJ. 2004; 329(7477): 1259, doi: 10.1 136/bmj.38272.478438.55, indexed in Pubmed: 15545293.

17. Darwood R, Earnshaw JJ, Turton G, et al. Twenty-year review of abdominal aortic aneurysm screening in men in the county 
of Gloucestershire, United Kingdom. J Vasc Surg. 2012; 56(I): 8-13, doi: 10.1016/j.jvs.2011.12.069, indexed in Pubmed: 22503187.

18. Matsumura Y, Wada M, Hirakawa D, et al. Clinical utility of transthoracic echocardiography for screening abdominal aortic aneurysm: a prospective study in a Japanese population. Cardiovasc Ultrasound. 2016; 14: 8, doi: 10.1 I86/s I2947-016-005 I-x, indexed in Pubmed: 26868661.

19. Corrado G, Durante A, Genchi V, et al. Prevalence of previously undiagnosed abdominal aortic aneurysms in the area of Como: the ComoCuore "looking for AAA" ultrasonography screening. Int J Cardiovasc Imaging. 2016; 32(8): |2 | 3-1217, doi: 10. 1007| s10554-016-09। I-3, indexed in Pubmed: 2721575।.

20. Hager J, Länne T, Carlsson P, et al. Lower prevalence than expected when screening 70-year-old men for abdominal aortic aneurysm. Eur J Vasc Endovasc Surg. 2013; 46(4): 453-459, doi: I0.1016/j.ejvs.2013.07.014, indexed in Pubmed: 2397856I.

21. Fukuda S, Watanabe $\mathrm{H}$, Iwakura $\mathrm{K}$, et al. Multicenter Investigations of the Prevalence of Abdominal Aortic Aneurysm in Elderly Japanese Patients With Hypertension. Circulation Journal. 2015; 79(3): 524-529, doi: 10.1253/circj.cj-14-0972.

22. Gianfagna F, Veronesi G, Tozzi M, et al. Prevalence of Abdominal Aortic Aneurysms in the General Population and in Subgroups at High Cardiovascular Risk in Italy. Results of the RoCAV Population Based Study. European Journal of Vascular and Endovascular Surgery. 2018; 55(5): 633-639, doi: 10.1016/j.ejvs.2018.01.008.
23. Svensjö S, Björck M, Wanhainen A. Current prevalence of abdominal aortic aneurysm in 70-year-old women. Br J Surg. 2013; 100(3): 367-372, doi: 10.1002/bjs.8984, indexed in Pubmed: 23192439.

24. Jahangir E, Lipworth L, Edwards TL, et al. Smoking, sex, risk factors and abdominal aortic aneurysms: a prospective study of 18782 persons aged above 65 years in the Southern Community Cohort Study. J Epidemiol Community Health. 2015; 69(5): 48 I-488, doi: 10.1 I36/jech-20 I4-204920, indexed in Pubmed: 25563744.

25. Pujades-Rodriguez M, George J, Shah AD, et al. Heterogeneous associations between smoking and a wide range of initial presentations of cardiovascular disease in 1937360 people in England: lifetime risks and implications for risk prediction. Int J Epidemiol. 2015; 44(I): |29-14|, doi: 10.1093/ije/dyu218, indexed in Pubmed: 2541672I.

26. Howard DPJ, Banerjee A, Fairhead JF, et al. Oxford Vascular Study. Age-specific incidence, risk factors and outcome of acute abdominal aortic aneurysms in a defined population. $\mathrm{Br} J$ Surg. 2015; 102(8): 907-915, doi: 10.1002/bjs.9838, indexed in Pubmed: 25955556.

27. Chun KC, Teng KY, Chavez LA, et al. Risk factors associated with the diagnosis of abdominal aortic aneurysm in patients screened at a regional Veterans Affairs health care system. Ann Vasc Surg. 2014; 28(I): 87-92, doi: 10.1016/j.avsg.2013.06.016, indexed in Pubmed: 24189004. 